\title{
Tubular Atrophy Assessment
}

National Cancer Institute

\section{Source}

National Cancer Institute. Tubular Atrophy Assessment. NCI Thesaurus. Code C135474.

An evaluation of the presence or degree of tubular atrophy present in a sample. 